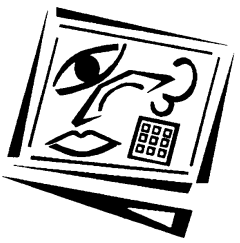

\title{
Using social network metrics to assess the effectiveness of broad based admission practices
}

\author{
Shane Dawson, Leah Macfadyen \\ University of British Columbia \\ Lori Lockyer and David Mazzochi-Jones \\ University of Wollongong
}

\author{
An Outstanding Paper Award recipient, ascilite Sydney 2010 Conference
}

\begin{abstract}
Notions of what it is to be knowledgeable and skilled in one's profession have evolved in recent decades. For instance, medical practitioners are expected to think critically and creatively, communicate effectively, and to be a professional and community leader. While these attributes have always been well regarded, it is only relatively recently that higher education institutions are actively incorporating these skills and attributes into student admissions criteria. In parallel, methods of instruction and course delivery have also changed over time with respect to these driving social paradigms. Today's medical schools are expected to both select and develop students in terms of these qualities through socially based pedagogical practices. This paper investigates the admissions criteria that best predict student engagement in a social learning environment and thus the related attributes such as communication, creativity, and leadership. The paper frames this investigation in the scholarship related to 21 st century skills and achievement orientations.
\end{abstract}

\section{Introduction}

Since the early massification of education, the process for university student admissions has long relied upon academic grades obtained through standardised testing practices. Advocates of this approach make the assumption that grades represent an essential measure of student preparedness and capacity for academic success at university (Barro, 2001). However, detractors frequently cite the negative impact of selection based purely on cognitive measures on student diversity and minority representation (Espenshade \& Chang, 2005). Regardless of the incentive, there is recent renewed interest among higher education institutions in adopting more broad-based admissions criteria. In essence, institutions are seeking criteria that act as early indicators of learner skills in the non-cognitive realm that are commonly referred to in university strategic statements about the qualities and attributes they will instil in their graduates. These may include elements of leadership, communication, innovation, and creativity.

In this paper we argue that admissions procedures that continue to rely heavily on standardised test scores impact not only student (academic, ethnic and cultural) diversity, but also dramatically affect the likelihood that admitted students will display desirable attributes such as creativity, lateral thinking and engagement in the 
course learning community. In so doing, we begin by demonstrating that grades-based reward and measurement schema are unlikely to encourage or select for the creativity, communication, networking and leadership attributes that are so urgently needed in the contemporary workforce. This argument is illustrated through analysis of student data that demonstrates the predictive variables associated with engagement in a learning community and course grades evolving from a broad-based admissions process. In short, the paper uses academic analytics data to address questions about the impact of broad-based admissions procedures on future student outcomes and teaching and learning practice.

\section{Student admissions}

The higher education environment has historically made heavy use of extrinsic motivators to reward and recognise achievement on learning related tasks. This is well illustrated in the assignment of and recognition of grades for specific learning deliverables. A further example can be found in the high stakes testing and recruitment practices for student admission into high profile vocational disciplines, such as medicine. In these instances, students are frequently streamed using selection processes that give priority to measures of their previous performance on academic tests. While admission processes to medical school may also incorporate an interview and demonstration of a portfolio, students are first filtered using criteria such as prior academic ability as evidenced through prior course grades and standardised test scores (e.g. Graduate Australian Medical School Admissions Test - GAMSAT). In this context, recruitment into a medical program is frequently weighted more heavily towards standardised testing (Powis, Hamilton \& McManus, 2007). These practices persist even though there is little research-based evidence that prior grades have any significant predictive power in relation to future academic performance (Groves, Gordon \& Ryan, 2007). The University of Queensland, for example, has recently discontinued the inclusion of an interview stage for medical student selection in preference for criteria relating solely to past grades and GAMSAT score.

In the higher education context this over-dependence on prior student grades may result in the selection of students with what Carol Dweck (2000) has previously termed a "high performance goal orientation". Dweck argues that two types of achievement orientations exist and these orientations largely reflect student motivation. For example, a learning goal orientation reflects a student's intrinsic motivation to develop new skills and knowledge. Conversely, a performance goal orientation relates to more extrinsic sources of motivation, such as the confirmation of knowledge and skills through the assignment of grades associated with various assessment tasks. Dweck highlights the conflict between an education system that is ideally promoting a learning oriented environment, whilst at the same time implementing practices that serve to promote a performance based culture. Simply put, grades win and what is assessed matters, and this leads directly to peer to peer competition, the antithesis of social learning behaviour.

In this context, the prevalence of admissions practices that draw too heavily upon student grades stresses a culture of competition and constant demonstration of performance. In such instances, the past experience and culture of students entering university life is one centred on direct competition with peers. Thus, based on this prior experience there is limited motivation for students to quickly develop networks, share resources, discuss and engage in learning activities. Furthermore, the skills 
required to commence these social network liaisons may be obstructed by their past experience of competition and performance. In essence, the reliance on grades as presumed evidence of cognitive capacity may be to the detriment of the various noncognitive dimensions of leadership, innovation, communication and creativity. These are attributes and skills that are best fostered in a learning environment complemented by a highly diverse student body, and frequent encounters with well-integrated curriculum activities that draw on the strengths of all peers (McWilliam, 2008; McWilliam \& Dawson, 2008; Yang \& Cheng, 2010). In short, student participation in engaged interactions within a social learning framework.

\section{Learning community - desirable attributes}

To date there has been much written about the vast educational benefits associated with a social learning pedagogy (see for example, Haythornthwaite, 2006; Lave, 1993; Seely Brown, 2006). Collectively, the literature on social learning suggests that active student participation within a diverse networked environment is critical for developing understanding, facilitating knowledge and resource exchange, and fostering 21stcentury skills and attributes such as creativity (Yang \& Cheng, 2010), leadership (Komives et al., 2009) and network agility (McWilliam, 2008). It cannot be emphasised enough that these oft cited and highly desirable attributes are largely developed through engaged social learning experiences. This raises an important question: If the possession of these attributes and skills, or the ability to develop them, are highly desirable, are these capacities adequately selected for and encouraged in student admission criteria? This study sought to identify the types of admissions criteria that would provide a lead indicator of student propensity for interacting within a community-centred pedagogy. We might ask: What are the types of admissions criteria that best predict student engagement in a learning community and thus the related attributes of creativity, leadership and network agility?

\section{Methodology}

In light of the above discussion, this study aimed to identify in student admissions data the potential predictors of student engagement in a learning community. In so doing, the study also sought to validate prior research relating to standardised medical test scores and future academic performance. Specifically, the study addressed the following research questions:

- What is the relationship between student admissions criteria and engagement in the learning community?

- Is there a significant relationship between prior student academic test scores and future academic performance in a medical education program?

The existence of correlations between medical student cohort admission scores, subsequent academic performance (end of year exam results) and social network data was examined (social network data such as centrality measures are sound indicators of the degree of student importance and level of engagement within the overall student learning community). The following section outlines the School's student admissions process and how the learning community data was extracted and measured for further statistical analysis and interpretation. 


\section{Study overview}

The study participants $(\mathrm{N}=132)$ included all first year enrolled medical students at an Australian university over a two-year period. Although the first year of study is more traditional in terms of course delivery (on campus classes) there is extensive curriculum integration with the institutional learning management system (LMS). The medical curriculum has been designed to rapidly familiarise and engage new students with the online resources and the associated learning activities. In this context, the medical program can be seen to be a blended pedagogical model integrating oncampus classes with online learning content and activities.

\section{Admissions process}

The graduate medical school's admissions process is rigorous and detailed. Admission is based on graduate level entry and demonstration of desirable skills and attributes. Applicants must address a diversity of admissions criteria including prior course grades (weighted GPA), GAMSAT score, and a portfolio demonstrating leadership and experience. These criteria are used to shortlist the potential applicants for a final interview stage. This stage involves a multiple mini-interview (MMI) in which each interviewee attends a number of timed interview stations each conducted by two trained assessors who provide a score for the applicant on their respective station (Eva, Rosenfeld, Reiter \& Norman, 2004). Questions at the interview stations are designed to uncover attributes such as critical thinking, decision making, communication skills, leadership, and knowledge of health care.

Aggregate scores for all criteria are then used as a cut off for offers to the program. The diversity of criteria used in the admissions process provides a unique opportunity to investigate which variables, if any, may act as significant indicators of future student engagement and overall preparedness and capacity for the medical profession.

International applicants are considered under an alternate interview system. As such, data for international students (representing $10 \%$ of the total combined cohort) have been excluded from this study.

\section{Measuring learning community engagement}

To determine student engagement within the online learning community the study extracted discussion forum data from the institutional LMS. The discussion forum data (exceeding 2000 individual posts) was analysed after completion of the first year of study for the 2007 and 2008 cohorts. The discussion forum is closely linked to the learning materials and activities. For instance, content reflecting specific medical cases is provided online for students to discuss collaboratively and decide on an appropriate medical course of action. In this context, the discussion forum is designed as collaborative medium for resource sharing and knowledge co-construction.

The forum data was extracted and analysed using the social networking software SNAPP (Bakharia \& Dawson, 2009) and Netdraw (Borgatti, 2002). The study adopted the social network extraction tool, known as Social Networks Adapting Pedagogical Practice (SNAPP) as a rapid means for exporting and analysing the established student relationships emerging through the discussion activity. SNAPP was developed as a "bookmarklet", a web link that activates a javascript to extract the forum interaction data for analysis and visualisation. The exported forum data was then analysed using 
Netdraw (Bakharia \& Dawson, 2009; Borgatti, 2002), a third party social network visualisation software program that allows calculation of network centrality properties such as degrees, closeness, betweenness and eigenvector.

In a learning community network, the centrality measure degrees describes the number of ties an individual student has established with other actors (students). A high number of degrees indicates that an individual has established many relationships that offer future opportunities for assistance with academic and social needs. The centrality measure closeness is defined as the degree of relationships an actor has formed with the entire network (Otte \& Rousseau, 2002). A betweenness measure commonly reflects an individual's potential access to information as it flows through the network. A student with a high betweenness score is well positioned to control the flow of information and resources throughout a learning network. Individuals with such positions in a network frequently act as bridges between otherwise isolated or disparate clusters (Burt, 2004). Lastly, the eigenvector measure is an indicator of a student's overall importance within the broader network structure (Faust, 1997). Briefly, eigenvector adopts a weighting system based on the centrality of all the connected nodes as well as the strength of the individual ties. The assumption is that the better connected nodes are rated more highly than their less well-connected peers. Thus, eigenvector provides a good indication of the value of an individual student's contribution to the learning community (see Wasserman and Faust (1994) for a more detailed overview of social network analysis).

\section{Assessment}

Student assessment scores were calculated from student performance on the final end of first year written exam. This final exam is used to determine student progression into second year of the medical course.

\section{Statistical analyses}

The admission, exam and community data were analysed using the software package SPSS for Windows (vers 18.0) incorporating descriptive statistics and a simple nonparametric correlation, to ascertain the degree of relationship between the investigated variables. The descriptive statistics indicated that the sampled population was a nonnormal distribution with respect to the reported admissions criteria. While this was anticipated as a result of the admissions screening processes, the subsequent statistical analyses necessitated the use of non-parametric statistical tests. In this instance the non-parametric test was Spearman's rank correlation. This test is frequently utilised when population samples demonstrate a non-normal distribution (Tabachnick \& Fidell, 2001). The reported statistical analyses were undertaken to investigate the relationship between student admissions criteria, end of year exam results and student engagement in the learning community. Learning community engagement was determined using social network centrality measures.

\section{Results}

\section{Participants}

The study included all first year domestic medical students for the $2007(\mathrm{n}=64)$ and $2008(n=68)$ calendar years $(\mathrm{N}=132)$. Females represented 56\% $(\mathrm{n}=74)$ and males $44 \%$ $(n=58)$ of the sampled population. The mean age of participants was $26.8(S D=4.34)$, 
with male sub-population slightly older than females reporting a mean age of 27.2 (SD $=4.17)$ and $26.5(\mathrm{SD}=4.47)$ respectively.

\section{Descriptive statistics}

Various descriptive statistics were generated to provide a quick overview of student admissions criteria scores and final exam results (Table 1). As the examined variables were calculated from alternate scales, the raw data was firstly standardised as Z scores to allow for assessment of covariance. While all sub-populations were comparable in results, there were some identified areas of significant difference (Table 1). For instance, a paired-sample $t$ test illustrates a significant difference between the 2007 and 2008 cohort scores relating to the interview and exam results, $\mathrm{t}(130)=6.58, \mathrm{p}<0.001$ and $t(130)=2.97, p<0.005$ respectively. Similarly, a significant difference was observed between female and male sub-populations relating to GPA, with females reporting a small, yet significantly higher GPA score $(t(130)=3.30, p<0.001)$.

Table 1: Mean and standard deviation for student Admissions criteria and final exam results

\begin{tabular}{|l|c|c|c|c|c|}
\hline & All & Female & Male & 2007 & 2008 \\
\hline GPA & 5.98 & $6.10^{*}$ & $5.84^{*}$ & 6.00 & 5.97 \\
& $(\mathrm{SD}=0.46)$ & $(\mathrm{SD}=0.45)$ & $(\mathrm{SD}=0.44)$ & $(\mathrm{SD}=0.44)$ & $(\mathrm{SD}=0.49)$ \\
\hline GAMSAT & 58.87 & 58.66 & 59.16 & 58.75 & 59.00 \\
& $(\mathrm{SD}=4.89)$ & $(\mathrm{SD}=5.16)$ & $(\mathrm{SD}=4.55)$ & $(\mathrm{SD}=3.71)$ & $(\mathrm{SD}=5.80)$ \\
\hline Portfolio & 27.64 & 27.2 & 28.2 & 28.91 & 26.46 \\
& $(\mathrm{SD}=7.37)$ & $(\mathrm{SD}=7.74)$ & $(\mathrm{SD}=6.9)$ & $(\mathrm{SD}=7.56)$ & $(\mathrm{SD}=7.03)$ \\
\hline Interview & 52.2 & 52.34 & 52.03 & $55.39 *$ & $49.20^{* *}$ \\
& $(\mathrm{SD}=6.20)$ & $(\mathrm{SD}=6.47)$ & $(\mathrm{SD}=5.89)$ & $(\mathrm{SD}=4.67)$ & $(\mathrm{SD}=6.00)$ \\
\hline Final 1st Year & 71.14 & 71.4 & 71.78 & $73.67^{* *}$ & $69.32^{* *}$ \\
exam & $(\mathrm{SD}=8.58)$ & $(\mathrm{SD}=9.51)$ & $(\mathrm{SD}=7.35)$ & $(\mathrm{SD}=6.69)$ & $(\mathrm{SD}=9.64)$ \\
\hline
\end{tabular}

${ }^{*}$ Indicates a significant difference between female and male sub-populations

** Indicates a significant difference between 2007 and 2008 cohorts

\section{Social network analysis}

The extraction of the discussion forum data and student developed relationships afforded an opportunity to re-create the social network. In this instance the network, and hence learning community engagement, is defined through the post and reply activity in the course discussion forum. Table 2 illustrates the social network centrality measures for the sampled population.

Table 2: Mean and standard deviation for student social network centrality measures

\begin{tabular}{|l|c|c|c|c|c|}
\hline & All & Female & Male & 2007 & 2008 \\
\hline Degrees & 6.95 & 7.62 & 6.10 & 5.23 & 8.57 \\
& $(\mathrm{SD}=7.90)$ & $(\mathrm{SD}=8.30)$ & $(\mathrm{SD}=7.33)$ & $(\mathrm{SD}=5.31)$ & $(\mathrm{SD}=9.49)$ \\
\hline Betweenness & 38.29 & 43.43 & 31.73 & 36.42 & 40.04 \\
& $(\mathrm{SD}=73.66)$ & $(\mathrm{SD}=83.55)$ & $(\mathrm{SD}=58.74)$ & $(\mathrm{SD}=55.28)$ & $(\mathrm{SD}=87.9)$ \\
\hline Closeness & 657.89 & 661.89 & 652.79 & 838.20 & 488.19 \\
& $(\mathrm{SD}=834.00)$ & $(\mathrm{SD}=791.61)$ & $(\mathrm{SD}=892.20)$ & $(\mathrm{SD}=888.19)$ & $(\mathrm{SD}=221.25)$ \\
\hline Eigenvector & 0.066 & 0.072 & 0.059 & 0.065 & 0.067 \\
& $(\mathrm{SD}=0.07)$ & $(\mathrm{SD}=0.07)$ & $(\mathrm{SD}=0.065)$ & $(\mathrm{SD}=0.067)$ & $(\mathrm{SD}=0.067)$ \\
\hline
\end{tabular}




\section{Admissions criteria and grades}

The student admissions data were correlated against students' end of first year performance as determined by their final awarded grades. The results indicate that prior student grades (GPA) and standardised tests (GAMSAT) are weak significant predictors of student first year academic performance $(\mathrm{r}=0.172, \mathrm{p}<0.05 ; \mathrm{r}=0.188, \mathrm{p}<$ 0.05 respectively). Interview scores also significantly correlated with student academic performance $(\mathrm{r}=0.253, \mathrm{p}<0.05)$. In essence, a student's previous test scores and interviews are significant indicators of future academic performance. The observed significant correlations also held true for each of the sub-populations - male, female, and 2007 and 2008 cohorts.

\section{Admissions criteria and learning community engagement}

In an attempt to identify lead indicators of student engagement within the course learning community, the social network centrality data were correlated against the student admissions criteria. In this instance the significant correlations were identified between interviews and closeness $(\mathrm{r}=0.311, \mathrm{p}<0.05)$, and between interviews and eigenvector scores $(r=0.152, p<0.05)$. The results indicate that no significant correlations exist between the SNA measures and GAMSAT and GPA criteria. Again, the correlation trend was largely replicated within the various sub-populations (Table $3)$.

Table 3: Correlation between social network centrality measures and student admissions criteria

\begin{tabular}{|l|l|c|c|}
\hline \multirow{5}{*}{ All students } & \multicolumn{1}{|c|}{$\begin{array}{c}\text { Centrality } \\
\text { measure }\end{array}$} & Interview & Portfolio \\
& Degrees & & \\
& Betweenness & & \\
\hline & Closeness & $\mathrm{r}=0.311$ & \\
& Eigenvector & $\mathrm{r}=0.152$ & \\
\hline Female & Degrees & & \\
& Betweenness & & \\
& Closeness & $\mathrm{r}=0.296$ & \\
\hline & Eigenvector & $\mathrm{r}=0.114$ & \\
\hline Male & Degrees & & \\
& Betweenness & & \\
& Closeness & $\mathrm{r}=0.308$ & \\
\hline & Eigenvector & $\mathrm{r}=0.171$ & \\
\hline 2007 Cohort & Degrees & & \\
& Betweenness & & \\
\hline & Closeness & $\mathrm{r}=0.198$ & \\
\hline & Eigenvector & & \\
\hline \multirow{2}{*}{2008 Cohort } & Degrees & $\mathrm{r}=0.296$ & \\
\hline & Betweenness & $\mathrm{r}=0.267$ & $\mathrm{r}=0.260$ \\
\hline & Closeness & $\mathrm{r}=0.333$ & \\
\hline & Eigenvector & $\mathrm{r}=0.280$ & $\mathrm{r}=0.263$ \\
\hline
\end{tabular}

Only variables of significance are listed $(p<0.05)$

No significant correlations were observed between centrality measures and GAMSAT and GPA criteria

Interestingly, the 2007 cohort demonstrated a significant correlation only between interviews and closeness. Modifications to the discussion forum structure for the 2008 cohort may have contributed to the stronger observed correlations in the later cohort in 
comparison to their 2007 peers. Additionally, the use of student portfolios to demonstrate desirable skills and attributes such as leadership was only demonstrated to have a significant relationship with community engagement measures in the 2008 cohort. In sum, these results indicate that student prior grades (GPA and GAMSAT scores) are not significant predictors of student capacity or willingness to engage in the course learning community.

\title{
Discussion
}

This study aimed to investigate the potential relationship between the various medical student admissions criteria, exam performance and engagement within the course learning community. The analysis of the results was based on the assumption that learning community engagement is an indicator that a student possesses the desirable skills and attributes that are reflective of stated university graduate outcomes. While this study is far from definitive, the preliminary results do indicate that medical student admissions based on prior test scores will pre-select for a cohort that is academically capable and largely prepared for university success. In this instance, success is narrowly defined as a measure of future exam performance and thus, the demonstration of discipline specific knowledge. The results of this initial study also suggest that so-called "soft skills" such as creativity, communication, collaboration and leadership are overlooked and unaccounted for in a grades-based admissions process. Herein lies the rub.

Universities internationally are focussing greater attention and resources towards the development of graduates who demonstrate the types of skills and attributes necessary for the conceptual age. In Daniel Pink's (2005) terms, the new workforce will be characterised by its capacity to re-contextualise existing products and services to value-add in short time frames. Workers in the conceptual age who possess both high concept and high touch aptitudes will be in greatest demand (Pink, 2005). Previously, these sorts of activities (complex conceptualisations merged with design and aesthetics) required skills that were commonly associated with the creative arts. However, numerous studies have recently challenged these notions, demonstrating that the skills and attributes frequently associated with creativity are essential for broad social and economic enterprise (Cunningham, 2006; Florida, 2004; Haring-Smith, 2006; Hartley, 2004). As Mihaly Csikszentmihalyi asserts, creativity is "no longer a luxury for the few, but... a necessity for all" (2006, p. xviii). The push and pull for the rise of these new combinations and complementary skills for the application of knowledge within an organisation is well summarised by Richard Florida and Jim Goodnight (2005), who note that:

\begin{abstract}
A company's most important asset isn't raw materials, transportation systems, or political influence. It's creative capital - simply put, an arsenal of creative thinkers whose ideas can be turned into valuable products and services. (p. 125)
\end{abstract}

The importance of developing creative capacity in learners is further emphasised in the recent European University Association's report on creativity in higher education (European University Association, 2007). In this report the EUA are emphatic in noting that higher education must equip graduates with the necessary skills to cope and prosper in a world that is characterised by constant change - a world that demands adaptability, flexibility and a tolerance for uncertainty. The call for these forms of creativity is also reflected in the Australian higher education sector. For instance, McWilliam and Dawson (2008) noted that 75\% of all Australian universities reference 
the term creativity in university strategic documentation such as graduate outcomes. However, the capacity to readily foster such skills is not necessarily selected for, nor promoted by a grade-based admissions process. While there are obvious workload implications associated with broad-based admission processes influencing the use of alternate metrics, it could be argued that these desirable skills and attributes can still be cultivated through learning and teaching practice.

As alluded to earlier in this paper, social learning has received much attention in the educational literature largely for its capacity to move curriculum emphasis from "what we are learning to how we are learning" (Brown \& Adler, 2008). A focus on how begins to describe the types of student engagements teachers can inculcate, through well designed activities and relevant content. In short, these types of learning engagements are frequently described as learning communities or communities of practice. It is through such ongoing social interactions that students foster skills such as leadership (Wang, 2010), creativity (Burt, 2004; Dawson, 2010), communication, and critical reasoning (Hakkarainen, Lipponen, \& Jarvela, 2002). Few would argue the merits of developing and implementing social learning activities. However, despite their best intentions, teachers may be faced with unforseen challenges associated with student motivations for collaboration. The results of this study suggest that some students are more motivated and able to pursue collaborations with their learning community earlier in the academic course than others. Medical students with high interview scores were more inclined to participate and engage in the student learning community than students with a low interview score.

This observation may reflect student motivation and goal alignment. For example, early research by Johnson and Johnson (1995) has demonstrated that participation within group activities is largely influenced by how well an individual's goals and motivations align with their fellow group members. The network analyses undertaken in the present study reinforce this point. It is not merely the number of unique relationships students have established (degrees) that correlate with interview scores. It is how important those relationships are in relation to the majority of the community. Interview scores therefore appear to select for students who are perceived to value add to the student learning community. Further investigation is required to discover whether it can be extrapolated from this idea that interview scores and social network measures are an early indicator of leadership and creative capacity.

Although admission based on grades are cost-effective, countries such as Canada that do not have a standardised testing process at either provincial or federal level are increasingly concerned about grade inflation. Grades awarded at the secondary school level impact future admission to university, and students are increasingly being offered opportunities to obtain additional grade credit to ensure they submit a strong and competitive admission application. For example, the Faculty of Arts at the University of British Columbia has observed a $7 \%$ increase in the cut off grade for admission to the Arts program (from $78 \%$ to $85 \%, 2002-2009$ ). While this increase reflects a growing applicant pool, it also illustrates the mounting competiveness for achieving high grades for university admission. As a result the university and associated faculties are recognising an opportunity to reduce the emphasis on grades, to include more criteria that would effectively increase the diversity, skills and attributes that reflect the ethos of the institution and its broad mandate.

Medical education has not been immune to the pressures for developing the more noncognitive personal qualities (Powis, 1994). The medical profession is a rapidly and 
constantly changing environment, in terms of the science, technology, governance, and communication practices. Emergent medical professionals require skills associated with communication, leadership, flexibility and a tolerance for change and uncertainty. The call for more development and associated recruitment for these creative skills and attributes within the medical profession is well promoted by Shee Lippell. For instance, Lippell (2002) argued that while the traditional medical school curriculum frequently suppresses the development of student creative skills, these are the very same skills that are necessary for developing "the 'doctors of tomorrow' that society requires" (p. 520). As in most professions, in addition to their discipline knowledge, medical practitioners require the capacity to problem solve, collaborate, and importantly communicate and translate information to a large diversity and range of stakeholders (specialists to generalists to lay people). Such skills are not developed in isolation, or through the emphasis on the admission of students on the basis of grades. Discipline knowledge is not the sole criteria by which our future medical graduates will be judged. The importance for fostering skills associated with safe and effective doctors and greater integration of alternate metrics for medical admission is well argued by McManus and Powis (2007) in noting that:

In medical school and beyond, most measures of competence assess knowledge,

whereas being a competent, safe and effective doctor probably depends to an equal extent on behaviour, attitudes and approaches. Adequate knowledge is a necessary part of good medicine, but is far from sufficient for competent practice. (p.118)

Given the need for, and obvious recognition of, the vast array of skills and attributes associated with effective medical practice, it is surprising that medical schools such as the University of Queensland have dismissed the relevance of interviews in favour of a greater emphasis on knowledge based assessments for student admission (McManus \& Powis, 2007; University of Queensland, 2010).

The results of this study indicate that while grades-based admissions processes select a student cohort who will perform well on future exams, they do not provide an indication of other, desirable graduate qualities that reside in the more non-cognitive domain. While there remains weighted emphasis on student assessment for admissions practices there will be a parallel promotion towards more performance base achievement orientations (Dweck, 2000). When performance on testing is the basis for admission, savvy students will rapidly prioritise tasks to ensure they remain highly competitive and ahead of the game.

\section{References}

Bakharia, A. \& Dawson, S. (2009). Social Network Adapting Pedagogical Practice (SNAPP) (Version 1.5) [Bookmarklet]. Brisbane, Australia.

Barro, R. J. (2001). Economic viewpoint: Why college shouldn't dump the SAT. Business Week, 9 April, 20.

Borgatti, S. P. (2002). NetDraw: Graph visualization software. Harvard: Analytic Technologies.

Brown, J. S. \& Adler, A. P. (2008). Minds on fire: Open education, the long tail, and learning 2.0. EDUCAUSE Review, 43(1), 16-32. http: / / net.educause.edu/ir/library/pdf/ ERM0811.pdf

Burt, R. (2004). Structural holes and good ideas. The American Journal of Sociology, 110(2), 349-399.

Csikszentmihalyi, M. (2006). Foreword: Developing creativity. In N. Jackson, M. Oliver, M. Shaw \& J. Wisdom (Eds.), Developing creativity in higher education: An imaginative curriculum (pp. xviii-xx). London: Routledge. 
Cunningham, S. (2006). What price a creative economy? Platform Papers: Quarterly Essay on the Performing Arts, No. 9. Sydney: Currency House.

Dawson, S. (2010). 'Seeing' the learning community: An exploration of the development of a resource for monitoring online student networking. British Journal of Educational Technology, 41(5), 736-752.

Dweck, C. (2000). Self-theories: Their role in motivation, personality, and development. Philadelphia: Psychology Press.

Espenshade, T. \& Chang, C. (2005). The opportunity cost of admission preference at elite universities. Social Science Quarterly, 86(2), 293-305.

European University Association (2007). Creativity in higher education. Brussels, Belgium: European University Association. [verified 2 Feb 2011] http: / / www.eua.be/typo3conf / ext/bzb_securelink/ pushFile.php?cuid=400\&file=fileadmin / user_upload/files/Publications / Creativity_in_higher_education.pdf

Eva, K. W., Rosenfeld, J., Reiter, H. I. \& Norman, G. R. (2004). An admissions OSCE: The multiple mini-interview. Medical Education, 38(3), 314-326.

Faust, K. (1997). Centrality in affiliation networks. Social Networks, 19(2), 157-191.

Florida, R. (2004). The rise of the creative class: And how it's transforming work, leisure, community and everyday life. New York, NY: Basic Books.

Florida, R. \& Goodnight, J. (2005). Managing for creativity. Harvard Business Review, 83(7), 124131.

Groves, M. A., Gordon, J. \& Ryan, G. (2007). Entry tests for graduate medical programs: Is it time to re-think? The Medical Journal of Australia, 186(3), 120-123.

Hakkarainen, K., Lipponen, L. \& Jarvela, S. (2002). Epistemology of inquiry and computersupported collaborative learning. In T. Koschmann, R. Hall \& N. Miyake (Eds.), CSCL 2: Carrying forward the conversation (pp. 129-156). Mahwah, New Jersey: Lawrence Erlbaum.

Haring-Smith, T. (2006). Creativity research review: Some lessons for higher education. Peer Review, 8(2), 23-27.

Hartley, J. (2004). The value chain of meaning and the new economy. International Journal of Cultural Studies, 7(1), 129-141.

Haythornthwaite, C. (2006). Learning and knowledge networks in interdisciplinary collaborations. Journal of the American Society for Information Science and Technology, 57(8), 1079-1092.

Johnson, D. W. \& Johnson, R. T. (1995). Social interdependence: Cooperative learning in education. In B. B. Bunker \& J. Z. Rubin (Eds.), Conflict, cooperation, and justice: Essays inspired by the works of Morton Deutsch (pp. 205-251). San Francisco, CA: Jossey-Bass.

Komives, S. R., Longerbeam, S. D., Mainella, F., Osteen, L., Owen, J. E. \& Wagner, W. (2009). Leadership identity development: Challenges in applying a developmental model. Journal of Leadership Education, 8(1), 11-47.

Lave, J. (1993). Situating learning in communities of practice. In L. B. Resnick, J. M. Levine \& S. D. Teasley (Eds.), Perspectives on socially shared cognition (pp. 17-36). Washington, DC: American Psychological Association.

Lippell, S. (2002). Creativity and medical education. Medical Education, 36(6), 519-521.

McManus, C., \& Powis, D. (2007). Testing medical school selection tests: Why is so little known about what works in selecting medical students? Medical Journal of Australia, 186(3), 118-119. 
McWilliam, E. (2008). The creative workforce: How to launch young people into high flying futures. Sydney: UNSW Press.

McWilliam, E. \& Dawson, S. (2008). Teaching for creativity: Towards sustainable and replicable pedagogical practice. Higher Education, 56(6), 633-643.

Otte, E. \& Rousseau, R. (2002). Social network analysis: A powerful strategy, also for the information sciences. Journal of Information Science, 28(6), 441-453.

Pink, D. H. (2005). A whole new mind. New York: Penguin.

Powis, D. (1994). Selecting medical students. Medical Education, 28, 443-469.

Powis, D., Hamilton, J. \& McManus, I. C. (2007). Widening access by changing the criteria for selecting medical students. Teaching and Teacher Education, 23(8), 1235-1245.

Seely Brown, J. (2006). New learning environments for the 21st century. Change, 6(5), 2-18.

Tabachnick, B. G. \& Fidell, L. S. (2001). Using multivariate statistics (4th ed.). Boston: Allyn \& Bacon.

University of Queensland (2010). School of Medicine: Domestic student admissions. [verified 2 Feb 2011] http: / / www2.som.uq.edu.au/som/FutureStudents/MBBS/ Admissions/ DomesticStudents/Pages/DomesticStudents.aspx

Wang, L. (2010). How social network position relates to knowledge building in online learning communities. Frontiers of Education in China, 5(1), 4-25. [verified 2 Feb 2011] http:/ / www.springerlink.com/index/5R7712095761Q21T.pdf

Wasserman, S. \& Faust, K. (1994). Social network analysis: Methods and applications. New York: Cambridge University Press.

Yang, H.-L. \& Cheng, H.-H. (2010). Creativity of student information system projects: From the perspective of network embeddedness. Computers E Education, 54(1), 209-221.

This article received an Outstanding Paper Award at ascilite Sydney 2010 Conference, gaining the additional recognition of republication in AJET (with minor changes including a revised title). The reference for the Conference version is:

Dawson, S., Macfadyen, L., Lockyer, L. \& Mazzochi-Jones, D. (2010). From neural to social: Medical student admissions criteria and engagement in a social learning environment. In Curriculum, technology \& transformation for an unknown future. Proceedings ascilite Sydney 2010. http:/ / ascilite.org.au/ conferences/sydney10/ Ascilite\%20conference\%20proceedings\%202010/Dawson-full.pdf

Dr Shane Dawson, Director ISIT, Faculty of Arts, University of British Columbia, Canada. Email: shane.dawson@ubc.ca

Leah Macfadyen, Science Centre for Learning and Teaching, University of British Columbia, Canada. Email: leah.macfadyen@ubc.ca

Lori Lockyer, Faculty of Education, University of Wollongong, Australia.

Email: llockyer@uow.edu.au

David Mazzochi-Jones, Graduate School of Medicine, University of Wollongong, Australia. Email: davidmj@uow.edu.au

Please cite as: Dawson, S., Macfadyen, L., Lockyer, L. \& Mazzochi-Jones, D. (2011). Using social network metrics to assess the effectiveness of broad based admission practices. Australasian Journal of Educational Technology, 27(1), 16-27.

http: / / www.ascilite.org.au/ajet/ajet27/dawson.html 